\title{
ESTUDO SOBRE AS CONDIÇÕES DAS PARADAS DE ÔNIBUS NA CIDADE DE SÃO PAULO
}

\author{
STUDY ON THE CONDITIONS OF THE BUS STOPS IN THE CITY OF \\ SÃO PAULO
}

Recebimento:22/11/2017- Aceite: 09/01/2018- Publicação: 28/01/2018

Processo de Avaliação: Double Blind Review

\begin{abstract}
Alex Wesley da Silva de Brito ${ }^{1}$
Graduado em Engenharia Civil

Universidade Nove de Julho

wesley.alex@gmail.com
\end{abstract}

Jefferson Constantino Santos

Graduado em Engenharia Civil

Universidade Nove de Julho

jeffersoncsantos2@gmail.com

Milene Azevedo Gonçalves

Graduado em Engenharia Civil

Universidade Nove de Julho

milene_azevedo03@hotmail.com

\section{Renan da Silva Marques}

Graduado em Engenharia Civil

Universidade Nove de Julho

renan.silvamarques@hotmail.com

\section{Adriane Monteiro Fontana}

Doutora em Engenharia de Transportes

Professora da Universidade Nove de Julho

adrianefontana@uol.com.br

\section{RESUMO}

O transporte coletivo por ônibus é um dos serviços mais utilizados em São Paulo, e as instalações necessárias a seu bom funcionamento são fundamentais. O objetivo deste trabalho foi mostrar a situação que se encontram os pontos de ônibus na cidade de São Paulo por meio de sua divisão por regiões (centro, norte, sul, leste e oeste) e compará-las com um ponto ideal, ou seja, que atenda a população de forma confortável e segura,

\footnotetext{
${ }^{1}$ Autor para correspondência: Universidade Nove de Julho. Av. Dr. Adolpho Pinto, 109 - Barra Funda, São Paulo - SP, Brasil.
}

Revista ENIAC Pesquisa, Guarulhos (SP), V.7, n.1, jan.- jun. 2018. 
incluindo pessoas portadoras de deficiências como cadeirantes e deficientes visuais. Foram realizadas pesquisas bibliográficas, de campo e de opinião, e pode-se concluir que as condições dos pontos existentes não são satisfatórias, sendo que um dos itens que a população julga mais importante é a cobertura em um ponto de ônibus, assim como a devida atenção as pessoas com deficiência, ou seja, aspectos básicos.

Palavra-chave: ponto de ônibus; paradas de ônibus; transporte público urbano.

\begin{abstract}
Public transportation by bus is one of the most used services in São Paulo, and the necessary facilities for its proper functioning are fundamental. The objective of this work was to show the situation of bus stops in the city of São Paulo through its division by regions (center, north, south, east and west) and to compare them with an ideal point, that is, that meet the population comfortably and safely, including people with disabilities such as wheelchairs and the visually impaired. Bibliographical, field and opinion surveys have been carried out and it can be concluded that the conditions of the existing points are not satisfactory, one of the items considered by the population to be more important is the coverage at a bus stop, as well as the due people with disabilities, that is, basic aspects.
\end{abstract}

Keywords: bus stations; bus stop; urban public transport.

\title{
1. INTRODUÇÃO
}

Para Boareto (2007), a produtividade e a qualidade na prestação dos serviços de transporte público, além de ser um anseio da sociedade moderna, tornaram-se um requisito indispensável para a eficiência do sistema, pois nas últimas décadas com o crescimento significativo da população das cidades, houve o deslocamento da população das áreas centrais para as áreas periféricas, ocasionando o aumento das distâncias entre morar e trabalhar, alongando o tempo de viagem e encarecendo os custos de locomoção.

Com base no exposto, aponta-se que as críticas referentes a qualidade do serviço de transporte por ônibus fazem parte do dia-a-dia dos usuários desse modo de locomoção.

Na cidade de São Paulo, segundo dados apresentados pela SPTRANS, existem cerca de 1.335 de linhas de ônibus que transportaram 2.915.344.011 pessoas no ano de 2016. Um indicador utilizado por essa empresa pública aponta que em média o tempo de espera nas paradas de ônibus monitoradas é de 12 minutos. Um outro indicador refere-se

Revista ENIAC Pesquisa, Guarulhos (SP), V.7, n.1, jan.- jun. 2018. 
ao tempo médio de deslocamento, e pode-se observar que no sentido bairro centro é de 63 minutos e, no centro bairro, 60 minutos.

Com base em tais informações, é possível afirmar que o tempo de espera nas paradas equivale, aproximadamente, a $20 \%$ do tempo em deslocamento. Sendo assim, é fundamental que as paradas de ônibus sejam objeto de estudo.

Essa pesquisa tem o intuito de verificar se os pontos de parada atendem as normas técnicas e também se são adequados para o uso dos usuários de transporte público sobre pneus da cidade de São Paulo. Para tal foi definido, a partir da literatura existente, o ponto de ônibus ideal, utilizado como base de comparação em campo na cidade de São Paulo. Além disso, foi pesquisado qual ou quais aspectos têm maior relevância para os usuários.

\section{METODOLOGIA}

A pesquisa foi realizada a partir de 3 etapas distintas:

a. Levantamento bibliográfico e de normas para a elaboração do ponto de ônibus ideal.

b. Estudo em campo para a análise dos pontos de ônibus existentes nas cinco regiões da cidade de São Paulo - SP.

Essa etapa do trabalho abrangeu a escolha de três bairros em cada uma das cinco regiões da cidade sendo elas: Norte, Sul, Leste, Oeste e Centro; deu-se de forma aleatória, assim como a dos pontos estudados. Foram estudados dez pontos por bairro. Num total de 150 na cidade. Os pontos foram analisados "in loco" com o uso de um checklist, elaborado a partir do ponto de ônibus ideal elaborado na etapa 01 do trabalho, além de um levantamento fotográfico. Com isto, foi possível apontar os problemas mais comuns nos pontos de paradas nas cinco regiões de SP, assim demonstrar as regiões - bairros mais precários, que necessitam de melhorias e reformas.

c. Pesquisa de opinião a usuários de transporte para entender o que é visto como importante para as pessoas. Foi elaborado um questionário para entrevistar os usuários, distribuído por meio de redes sociais com caráter empírico.

\section{PROPOSTA DE PONTO DE ÔNIBUS IDEAL}

Primeiramente é fundamental entender que um ponto de ônibus deverá atender a todos os cidadãos, com isto, os primeiros aspectos para um ponto ideal devem atender a

Revista ENIAC Pesquisa, Guarulhos (SP), V.7, n.1, jan.- jun. 2018. 
legislação referente a acessibilidade no país. Salienta-se aqui que o Instituto Brasileiro de Geografia de Estatística (2010) revelou que em 2010, 23,9\% a população brasileira que apresenta algum tipo de deficiência.

Portanto, é necessário ter um espaço reservado nos pontos de ônibus para o cadeirante, com uma projeção da cadeira de rodas para indicar que aquele lugar é reservado para ele, conforme preconiza ABNT (2015), além claro, de outros aspectos referentes as demais deficiências.

Para que não atrapalhe a circulação das pessoas na calçada, a norma informa que o ideal é ter uma faixa livre de $1.20 \mathrm{~m}$ e especifica que na falta de espaço pode-se adotar uma faixa livre de $0.90 \mathrm{~m}$. Para a garantia de manobra do cadeirante é preciso que sejam eliminadas as interferências físicas no ponto. (ABNT, 2015). A figura 1 mostra uma ilustração do que foi citado.

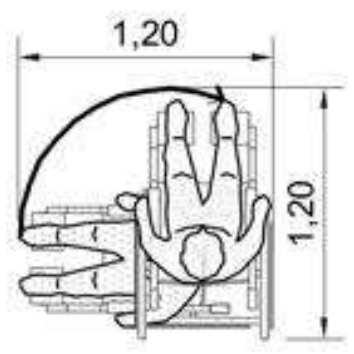

a) Rotação de $90^{\circ}$

Figura 1 - Rotação para cadeirante

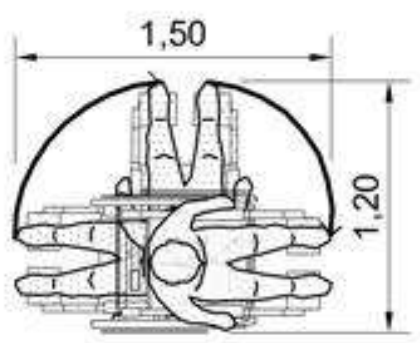

b) Rotação de $180^{\circ}$

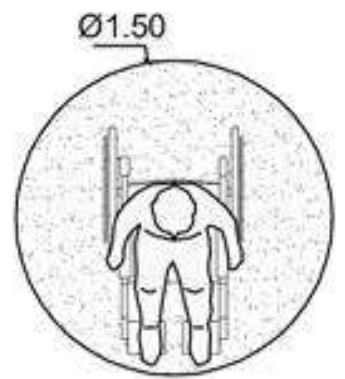

c) Rotação de $360^{\circ}$

Fonte: ABNT, 2015.

Ainda referente a acessibilidade, um outro fator importante nos pontos de parada é a necessidade da sinalização tátil no piso, contendo tanto a direcional e quanto a de alerta. Sendo o alerta para atentar deficiente visual quando há um obstáculo que ele não consiga rastrear com a bengala e o direcional serve para conduzir e orientar no trajeto. Dessa forma, é possível dar maior independência e potencializar a capacidade das pessoas com deficiência, direcionando aos lugares exatos e evitando maiores acidentes. A figura 2 apresenta a sinalização de alerta (vermelha) e direcional (amarela).

Figura 2 - Piso tátil

Revista ENIAC Pesquisa, Guarulhos (SP), V.7, n.1, jan.- jun. 2018. 


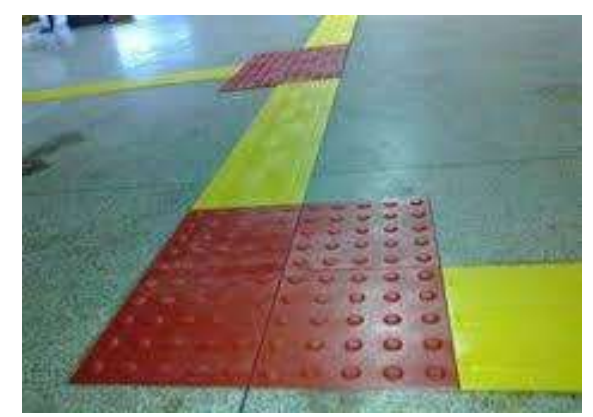

Fonte: Total Acessibilidade; 2018.

Além de aspectos relacionados a acessibilidade, é fundamental proporcionar conforto e proteção as intempéries aos usuários do sistema de transporte, dessa forma, deve-se salientar a grande relevância da existência de abrigos nos pontos de. Os abrigos podem contemplar somente a cobertura, o também a cobertura com o fechamento lateral. Podem ser feitos com diversos materiais, tais como metal, vidro, madeira e concreto.

A primeira iteração que o usuário tem com transporte público é o abrigo de ônibus, o que pode encorajar o uso dessa modalidade de transporte. Todavia, existe uma distinção clara entre a expectativa dos usuários e os gestores do sistema em relação a tais instalações. Por parte da gestão, é esperado que o material utilizado para construção seja resistente, assim como tenha um baixo custo e manutenção reduzida. Já os usuários esperam um tamanho adequado, com boa aparência, distancia adequada entre os pontos, iluminação suficiente e o mais importante, painéis informativos sobre localização e horários. (ANTUNES e SIMÕES; 2013; p.52).

Os autores supracitados apresentaram dez atributos para a qualidade do transporte público por ônibus a partir dos estudos realizados por FERRAZ e TORRES (2004), que discorreram sobre os pontos apontando como uma característica crucial a existência de cobertura, além, claro, da presença de uma sinalização adequada e bancos para usuários se sentarem.

Um outro aspecto salientado é a respeito da localização dos pontos, que é importante uma boa localização em lugares onde há uma grande movimentação como regiões industriais e comerciais. Deve atentar-se para que os pontos de ônibus não sejam instalados próximos a lugares onde há esquinas, curvas e interseções, pois nessas regiões podem ocorrer acidentes, (FERRAZ e TORRES; 2004).

Quanto a sinalização de trânsito necessária nos pontos de ônibus, deve-se apontar que tanto a vertical quanto a horizontal são fundamentais, para evitar que outros tipos de 
veículos estacionem nos pontos e prejudique a operação. Os manuais de sinalização em vigor no país apontam que os locais devem ser sinalizados com placas verticais nas dimensões $0.40 \times 0.60 \mathrm{~m}$ (figura 3), além da sinalização horizontal, composta por faixas pintadas em amarelo e a palavra ônibus escrita no pavimento na cor branco, conforme figura 4.

Figura 3 - Placa

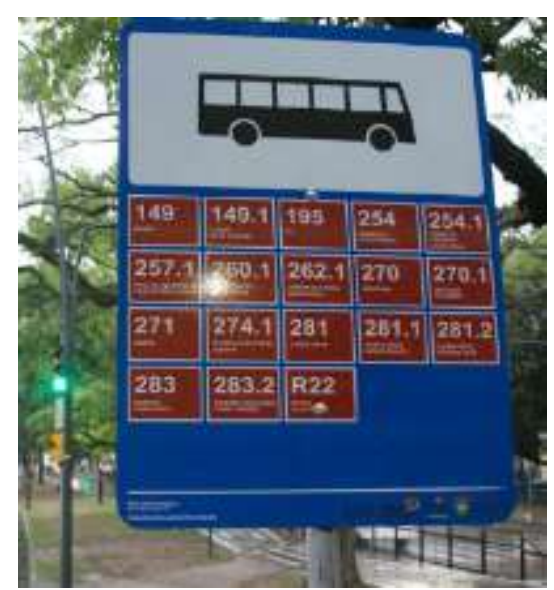

Fonte: São Paulo. CET; 2017.

Figura 4 - Sinalização Horizontal

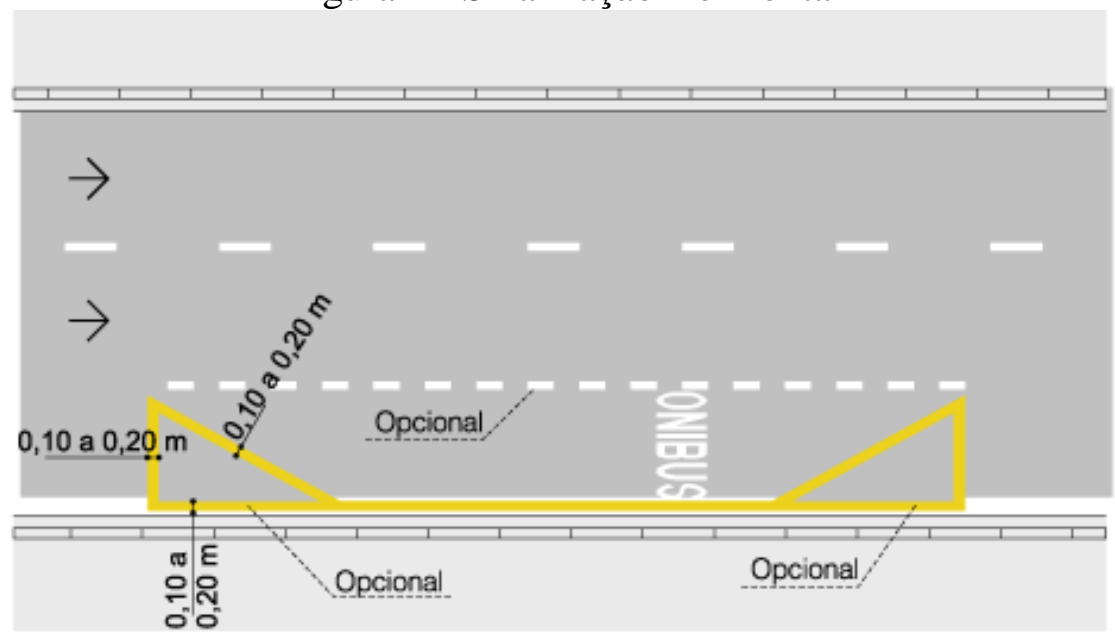

Fonte: CONTRAN; 2007; p. 71

Já a localização dos pontos, por razões de segurança, não deve ser em curvas, rampas acentuadas ou muito próximas a cruzamentos. No que se dizem respeito à

Revista ENIAC Pesquisa, Guarulhos (SP), V.7, n.1, jan.- jun. 2018. 
localização, os pontos de parada podem estar antes do cruzamento, depois do cruzamento ou no meio da quadra, sendo o último o mais recomendado. (ABNT; 2015).

Quanto as guias existentes nas calçadas, Ferraz e Torres (2004; p. 244) afirmam que "Existem três tipos de posição de guia das que podemos utilizar sendo elas: guia normal, que é a mais utilizada, guia recuada tipo baia e guias avançadas”. A guia na posição normal permite a parada do ônibus do lado direito ou esquerdo da via, já a baia recuada proporciona um tráfego de carros mais fácil, porém dificulta a volta dos coletivos para o fluxo de tráfego quando o trânsito é intenso, proporcionando atrasos nos horários. Os aspectos analisados na hora da escolha da posição da guia são a fluidez do trânsito no local, comodidade dos usuários e a facilidade do retorno do ônibus ao trafego. A figura 5 mostra os tipos estabelecidos.

Outro item importante para se empregar em um ponto de ônibus é a lixeira, pois evita que usuários do ponto joguem lixo no chão, assim promove a organização e limpeza do local.

Um outro aspecto importante é a existência de um painel informativo instalado nos pontos de ônibus, com informações referentes aos ônibus, linhas, horários e itinerários, que facilita muito para o usuário além de considerar que nem todos tem acesso à internet o todo tempo ou sabe usá-la para pesquisar essas informações.

Revista ENIAC Pesquisa, Guarulhos (SP), V.7, n.1, jan.- jun. 2018. 
Figura 5-Tipos de Guias

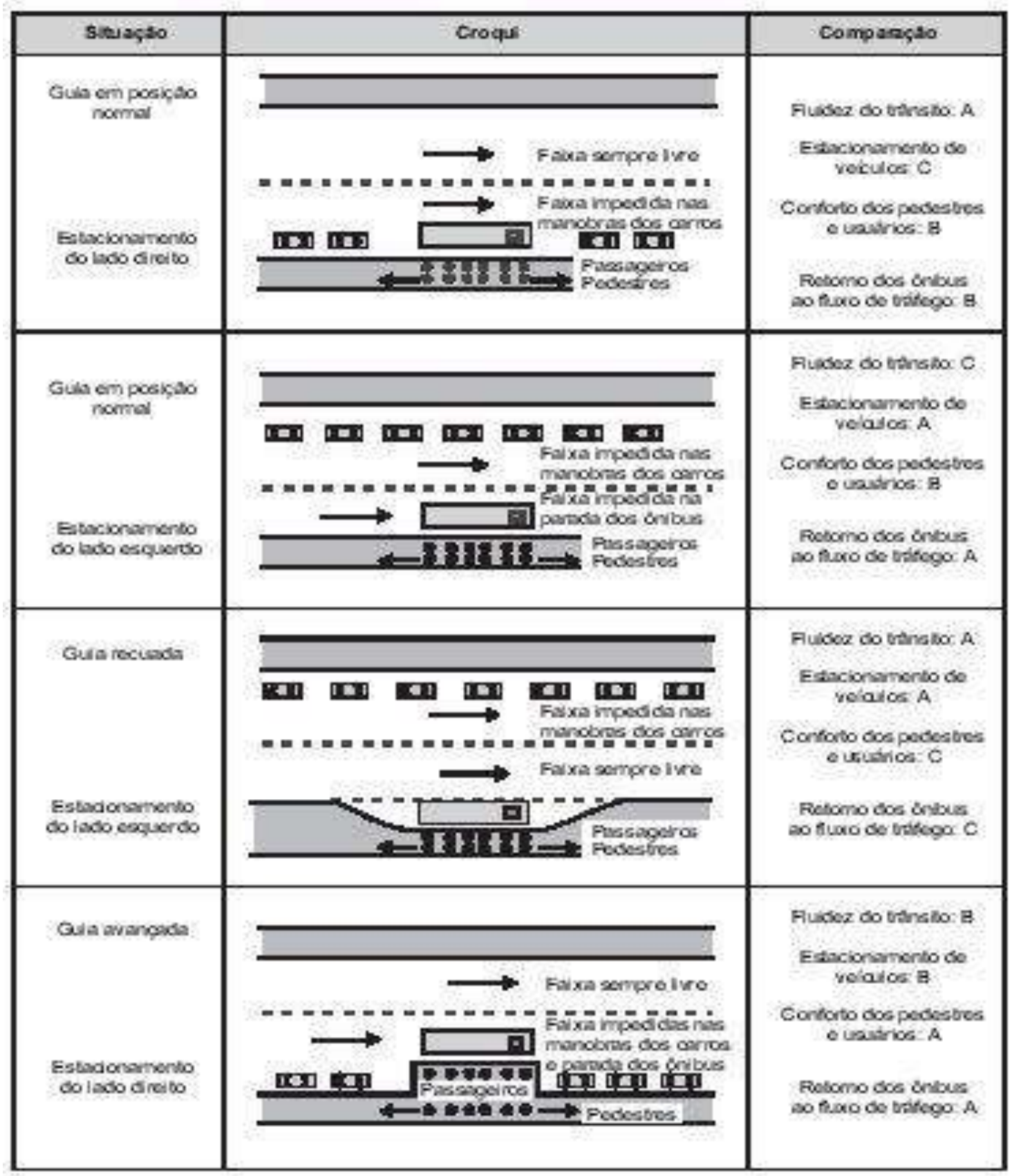

Fonte: FERRAZ e TORRES; 2004; p. 243.

A iluminação nos pontos de ônibus deveria ser indispensável, pois promove aos usuários mais segurança e conforto.

O ponto de parada ideal idealizado nesse trabalho contém:

- Cobertura de maior alcance que também serve para proteger o usuário do intemperismo;

Revista ENIAC Pesquisa, Guarulhos (SP), V.7, n.1, jan.- jun. 2018. 
- Proteção transparente nas laterais do abrigo, para facilitar a visualização do usuário além de protegê-lo quanto ao intemperismo;

- Fechamento dos fundos do abrigo para impedir que o vento e chuva atinjam o interior do abrigo;

- Assentos em maior número para proporcionar mais conforto para os usuários;

- Espaço reservado para cadeirantes sinalizado;

- Piso tátil para auxiliar os deficientes visuais;

- Lixeira para limpeza do meio;

- Painel digital com sistema de informações das linhas que passam pelos pontos, horário, intervalo entre veículos e itinerário;

- Sinalização vertical e horizontal.

Todos os itens elencados foram baseados nas normas e literaturas consultadas, sendo que alguns não são obrigatórios, mas de grande valia para os usuários. Nas figuras 6 e 7 é possível observar o croqui do ponto ideal.

Figura 6-Vista frontal croqui de um ponto de ônibus ideal

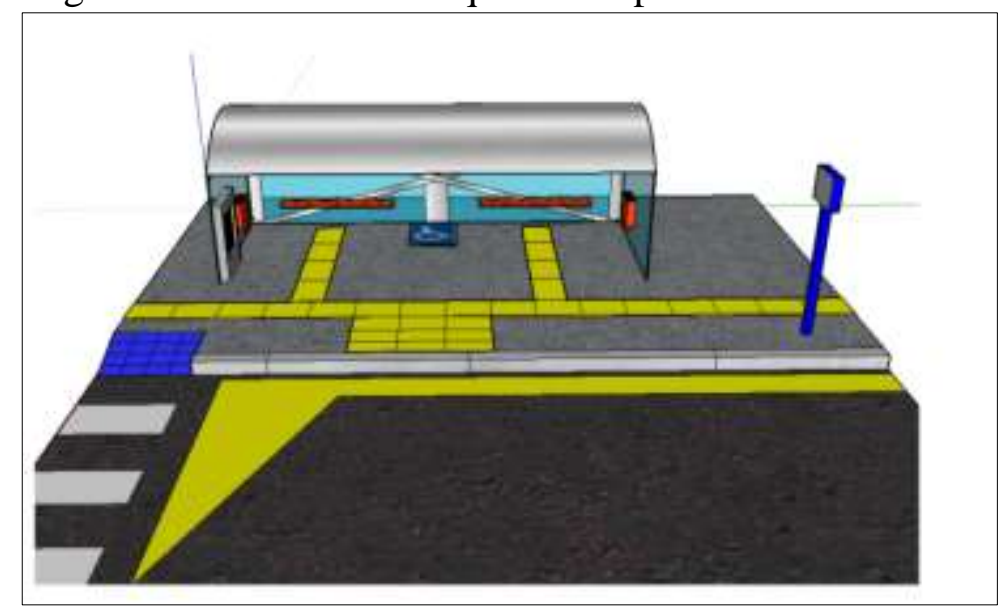

Fonte: Autores; 2017.

Revista ENIAC Pesquisa, Guarulhos (SP), V.7, n.1, jan.- jun. 2018. 
Figura 7-Vista lateral croqui de um ponto de ônibus ideal

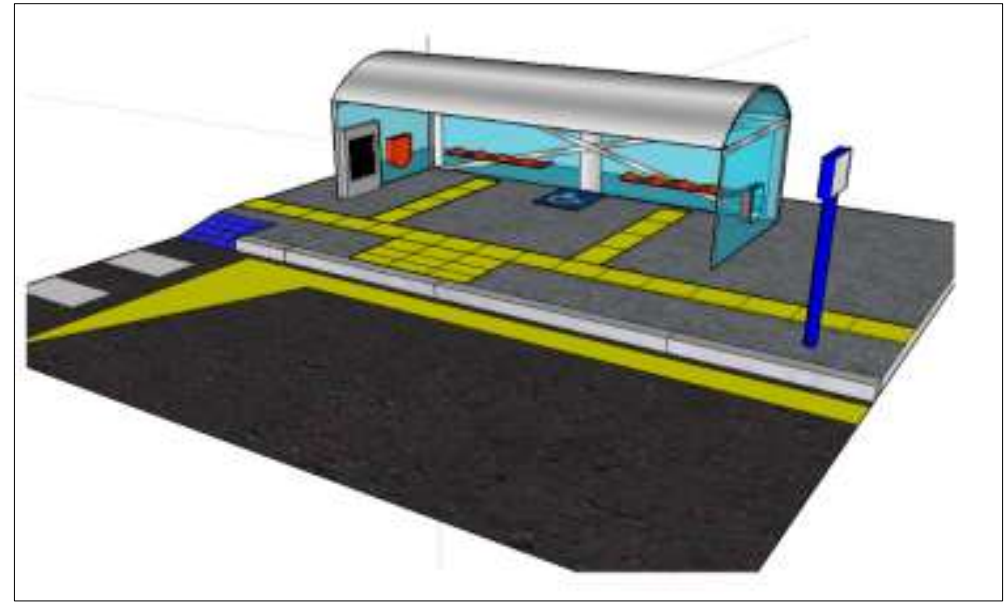

Fonte: Autores; 2017.

\section{PESQUISAS REALIZADAS}

O presente trabalho realizou duas investigações, sendo um levantamento dos pontos de ônibus em campo e uma pesquisa de opinião com usuários do transporte público por ônibus na cidade de São Paulo.

\subsection{LEVANTAMENTO EM CAMPO}

Foi realizada uma pesquisa de campo em cinco regiões de São Paulo sendo elas: Zona Leste, Zona Sul, Zona Oeste, Zona Norte e Centro. A pesquisa seguiu um questionário que compreendia os principais itens que um ponto de ônibus deve atender.

O questionário continha: local da pesquisa, se o ponto de ônibus tinha cobertura e a qualidade do mesmo, se tinha bancos e sua qualidade também, paneis informativos com horário e linhas que passam pelo ponto analisado, sinalização com placas verticais indicando que aquele local é um ponto de ônibus, qual é o tipo de material do ponto, sinalização no chão com piso tátil, se tem lixeira e o estado dela, se há iluminação no ponto, se atende a acessibilidade, circulação geral para os usuários e a localização desse ponto de ônibus. Para cada zona pesquisada na cidade de São Paulo foi elaborado um gráfico para analisar os itens dos pontos de ônibus estudados a luz do ponto ideal elaborado nesse trabalho.

Revista ENIAC Pesquisa, Guarulhos (SP), V.7, n.1, jan.- jun. 2018. 
Foi realizado um mapeamento dos pontos de ônibus nas cinco zonas do município de São Paulo, sendo que em cada uma delas foram analisados três bairros com 10 pontos em cada um deles.

\subsection{PESQUISA COM OS USUÁRIOS}

Para maior entendimento sobre as condições dos pontos de ônibus da nossa cidade foi realizada uma pesquisa de opinião para conhecer o que os usuários consideram primordial em um ponto de ônibus, bem como quais melhorias julgam necessárias para tais instalações. Foi construído um questionário utilizando a plataforma do Survio, que possibilitou a coleta de respostas via internet. O link do questionário com a descrição da pesquisa ficou disponível para o recebimento de respostas durante 15 dias no mês de outubro de 2017. A pesquisa foi amplamente divulgada em redes sociais em modo público.

\section{RESULTADOS OBTIDOS}

\subsection{RESULTADOS OBTIDOS NA PESQUISA DE CAMPO.}

Para uma melhor compreensão dos dados obtidos, os resultados foram apresentados por região, e posteriormente, no conjunto do município.

\subsubsection{Resultados da Zona Leste}

Os primeiros pontos de ônibus verificados foram nos bairros da Zona Leste, sendo eles Itaquera, Guaianases e Vila Prudente, e em cada bairro foram analisados 10 pontos de ônibus. Por meio dos dados obtidos foi construído um gráfico, que apresenta o percentual de itens existentes nos pontos da região. A figura 8 demostra o gráfico gerado da Zona Leste de São Paulo.

Revista ENIAC Pesquisa, Guarulhos (SP), V.7, n.1, jan.- jun. 2018. 
Figura 8 - Gráfico da Zona Leste

\section{ZONA LESTE}

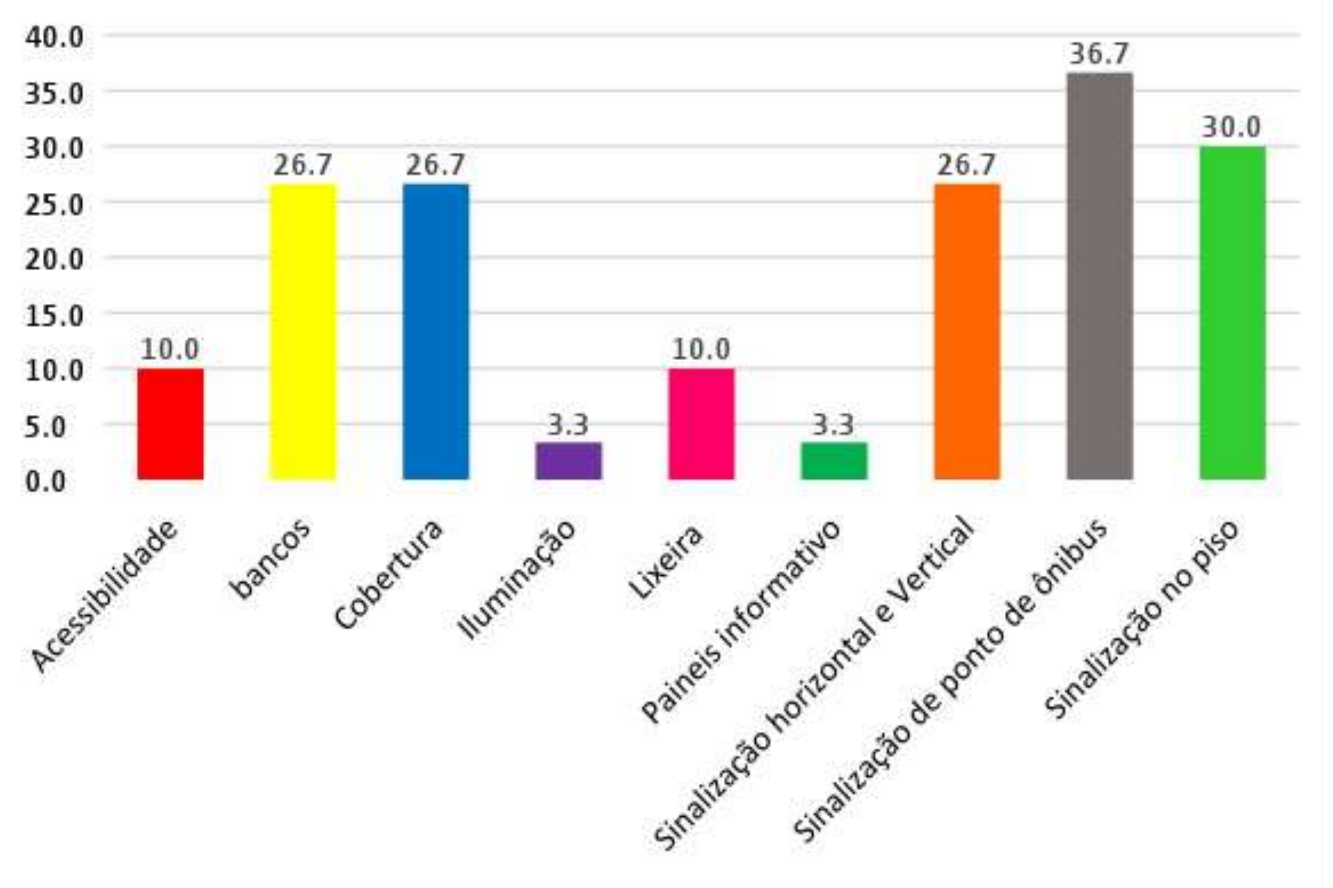

Fonte: Autores; 2017.

Os resultados obtidos do gráfico se referem ao percentual dos itens de 30 pontos de ônibus da Zona Leste, e o gráfico mostra que o item com percentual mais alto de existência nos pontos foi de sinalização de ponto de ônibus com $36,67 \%$, porém feita de madeira. Os itens com menor percentual foram iluminação e painéis informativos, com apenas $3,33 \%$.

A lixeira, cobertura, banco e acessibilidade que também são de extrema importância, não passaram de $26 \%$, esse valor mostra o quanto ainda a região da zona leste tem a melhorar. Outro ponto que foi analisado é o estado desses elementos, como coberturas e bancos que se encontram quebrados.

Revista ENIAC Pesquisa, Guarulhos (SP), V.7, n.1, jan.- jun. 2018. 


\subsubsection{Resultados do Centro}

Os resultados obtidos no gráfico se referem aos bairros do centro - Liberdade, Santa Cecilia e Consolação - assim como nas demais zonas foram 10 pontos de cada bairro analisado. A figura 9 mostra o gráfico do centro.

\section{Figura 9 - Gráfico Centro}

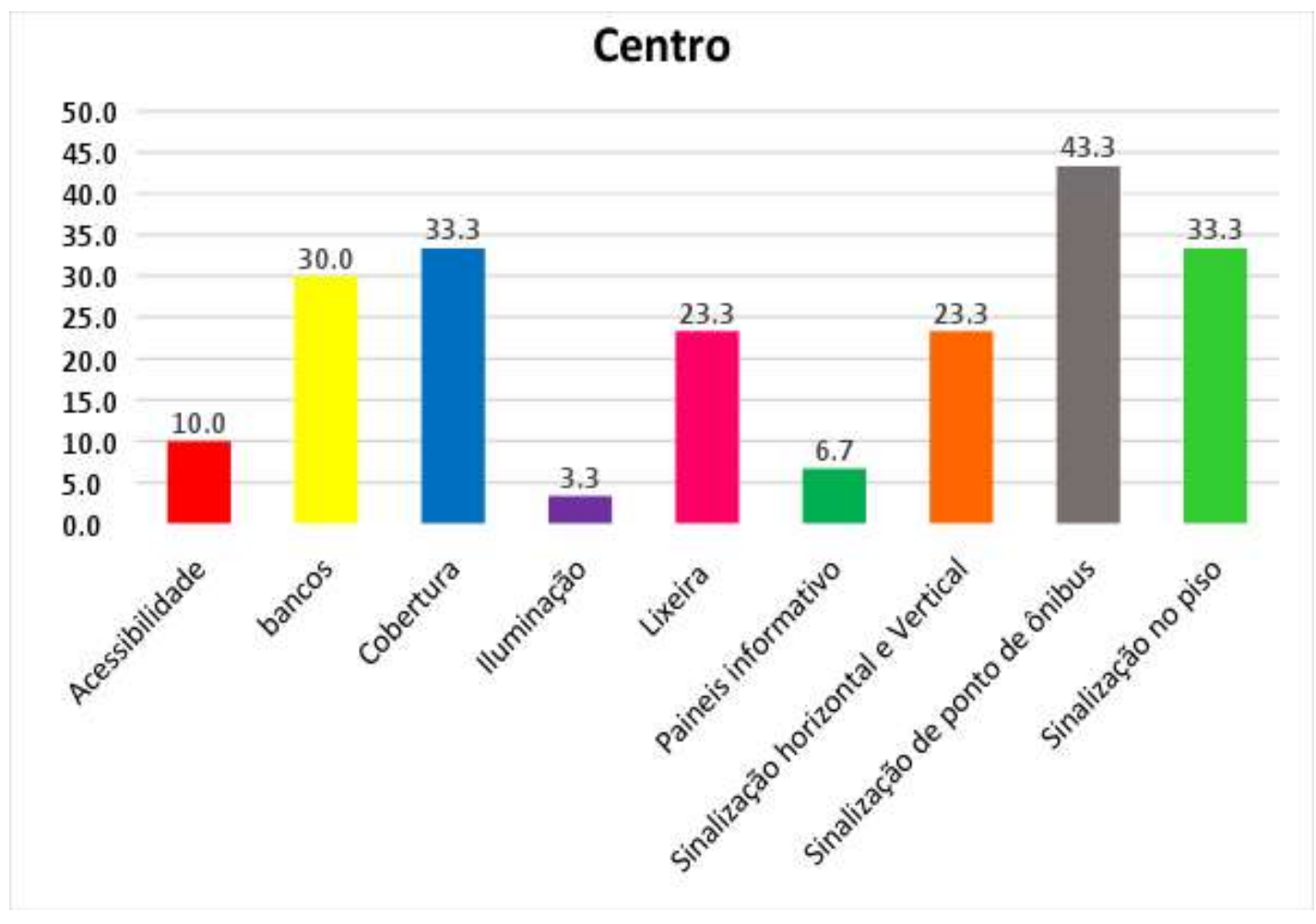

Fonte: Autores; 2017.

Assim como a Zona Leste, a sinalização de ponto de ônibus teve o maior percentual de existência com $43,3 \%$, porém de madeira também. Com a porcentagem menor temos iluminação novamente com apenas 3,3\% e painéis informativos com $6,7 \%$. A lixeira, cobertura, banco e acessibilidade, placas verticais e sinalização do piso, chegaram até $33 \%$, o resultado foi um pouco melhor que a Zona Leste, mas ainda não atingiu uma margem de resultados satisfatória.

Revista ENIAC Pesquisa, Guarulhos (SP), V.7, n.1, jan.- jun. 2018. 


\subsubsection{Região Sul}

Na Zona Sul foram analisados os bairros do Morumbi, Santo Amaro e Campo Limpo, com os dados obtidos foi realizado o gráfico, como mostra a figura 10 a seguir:

Figura 10 - Gráfico Zona Sul

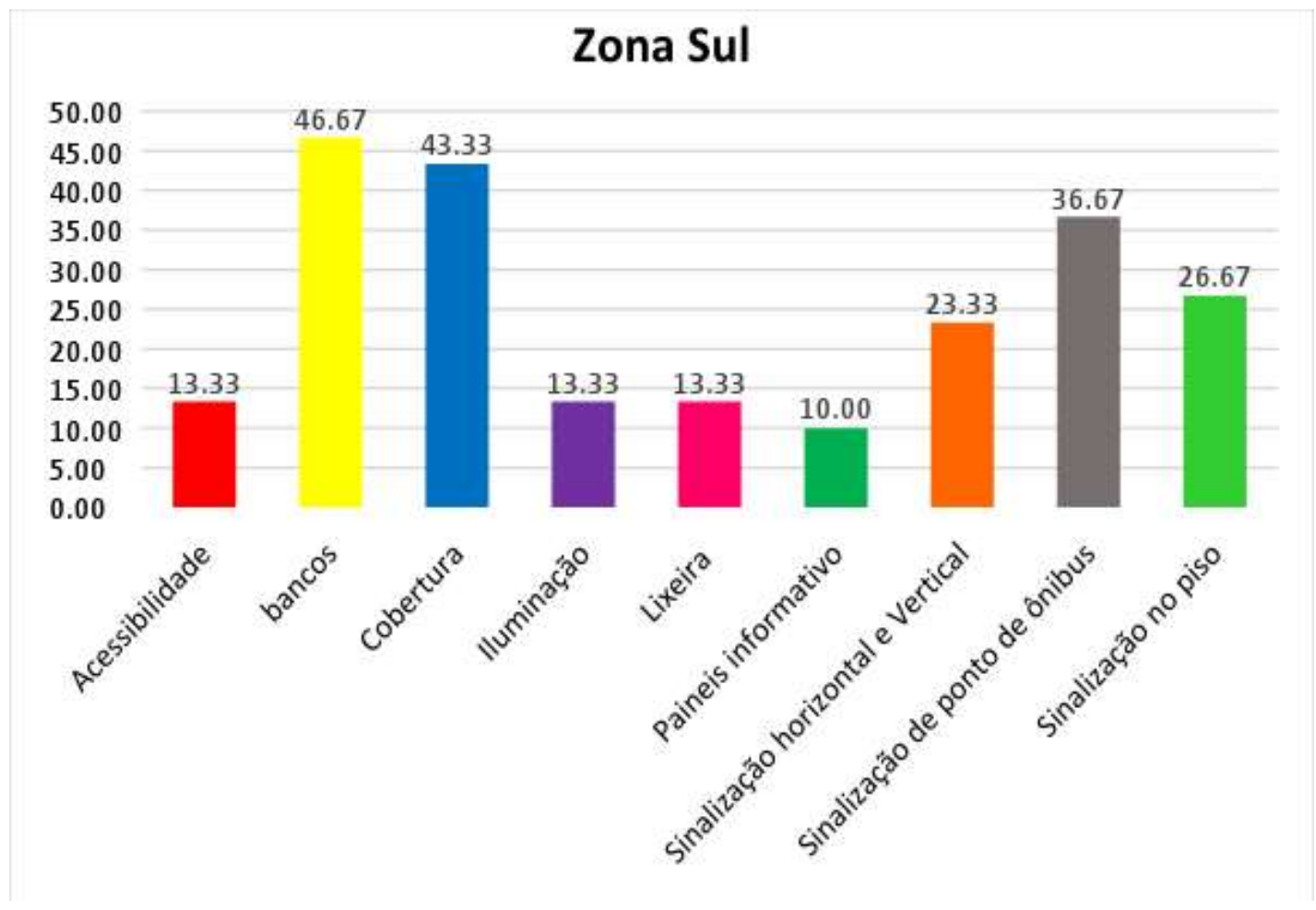

Fonte: Autores; 2017.

Analisando o gráfico da Região Zona Sul, temos o item banco com um percentual de existência mais elevado, com 46,67\%, e cobertura com 43,33\%. E com menor percentual temos a iluminação e lixeira com 13,33 \%. Já acessibilidade, painéis informativos, placas verticais, sinalização no piso e sinalização do ponto de ônibus não passaram de $36,67 \%$.

Mesmo tendo um melhor desempenho, essa zona ainda tem muito a melhorar.

Revista ENIAC Pesquisa, Guarulhos (SP), V.7, n.1, jan.- jun. 2018. 


\subsubsection{Resultados da Zona Norte}

Nessa região foram analisados os bairros de Santana, Casa Verde e Tucuruvi. O gráfico gerado da pesquisa consta na figura 11.

Figura 11 - Gráfico Zona Norte

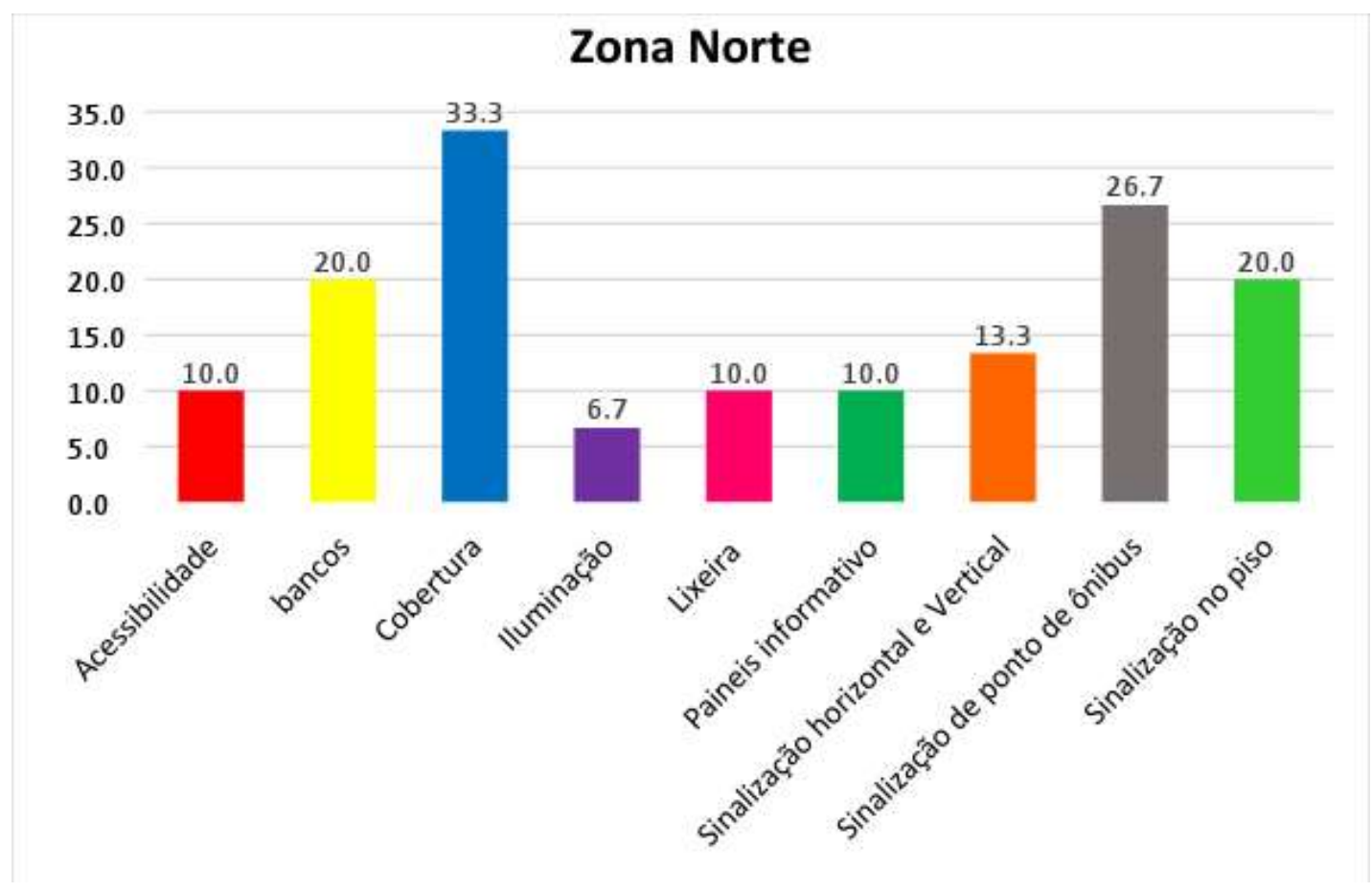

Fonte: Autores; 2017.

Com percentual mais alto nos pontos, tem-se a cobertura em 33,33\% deles e sinalização no piso, em $26,67 \%$. Já com o menor percentual temos a iluminação com $6,67 \%$. Já bancos, lixeira, painéis informativos e placas verticais não passaram de $20 \%$, um número baixo para esses itens tão fundamentais.

Revista ENIAC Pesquisa, Guarulhos (SP), V.7, n.1, jan.- jun. 2018. 


\subsubsection{Resultados da Zona Oeste}

Na Região Oeste foram analisados os pontos nos bairros: Butantã, Vila Sônia e Barra Funda. Com os dados obtidos temos gráfico como mostra a figura 12.

Figura 12 - Gráfico Zona Oeste

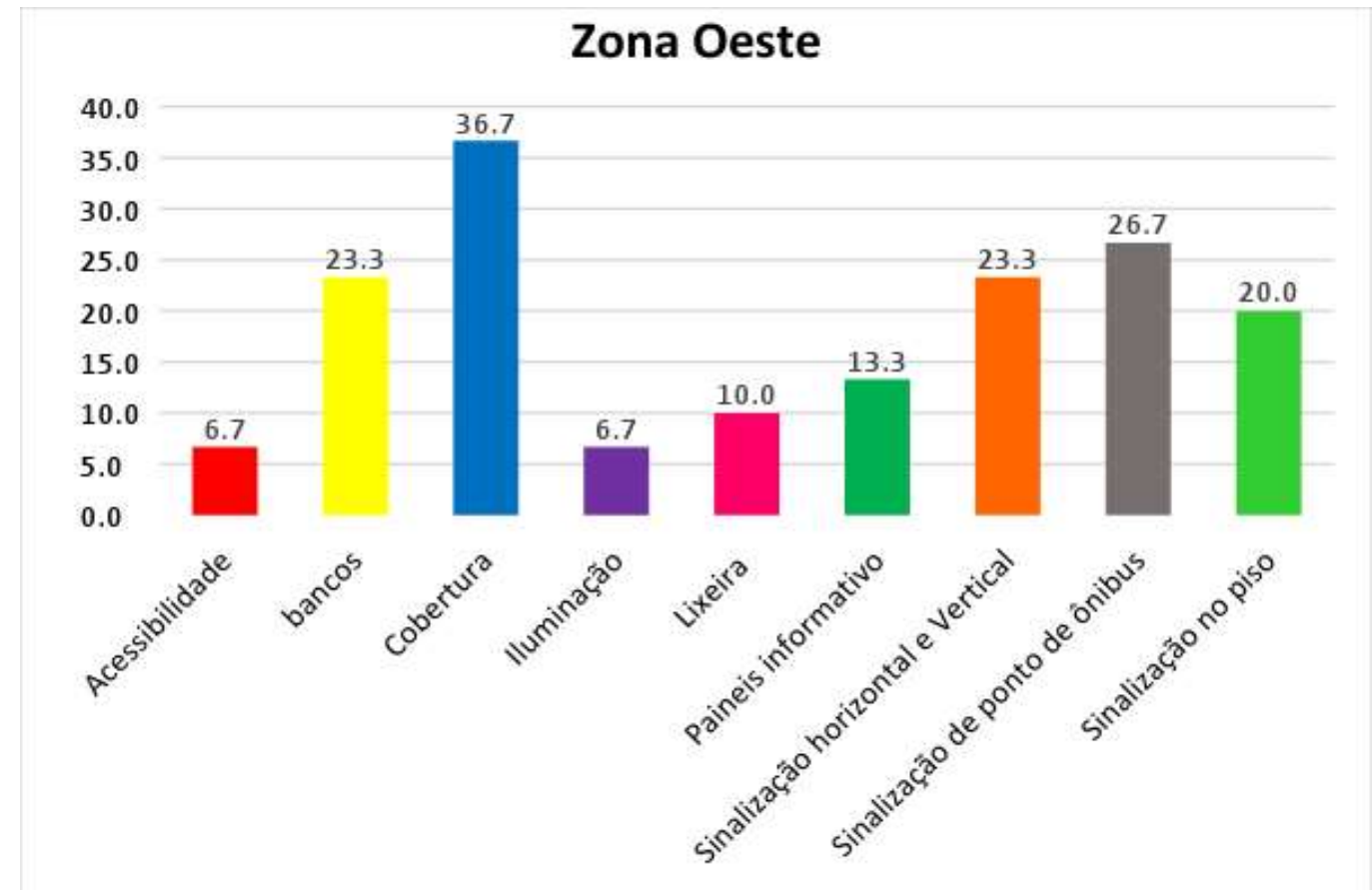

Fonte: Autores; 2017.

Com percentual mais alta da zona Oeste temos cobertura e sinalização do ponto de ônibus. Já o grande problema com menor porcentagem é a iluminação com 6,67\% e lixeira com $10 \%$. Os demais itens não chegaram ao número de $20 \%$.

\subsubsection{Resultado Global da Cidade de São Paulo}

De acordo com o levantamento das 5 zonas da cidade de São Paulo, verificou-se que o problema é geral e estamos muito distantes do ideal, pois ainda há muito trabalho a ser feito. Dos 150 pontos de ônibus verificados, apenas 35\% desses pontos tinham coberturas, $34 \%$ estavam devidamente sinalizados como ponto de ônibus, $29 \%$ continham bancos, $26 \%$ tinham sinalizações de piso e em apenas $22 \%$ haviam placas verticais e horizontais. Os demais itens como lixeira, iluminação, acessibilidade e painéis informativos, nem mesmo chegam a atingir $15 \%$, mesmo sendo considerado como itens muito importantes pela maioria dos usuários.

Revista ENIAC Pesquisa, Guarulhos (SP), V.7, n.1, jan.- jun. 2018. 
Figura 13 - Gráfico com a Somatória de todas as regiões

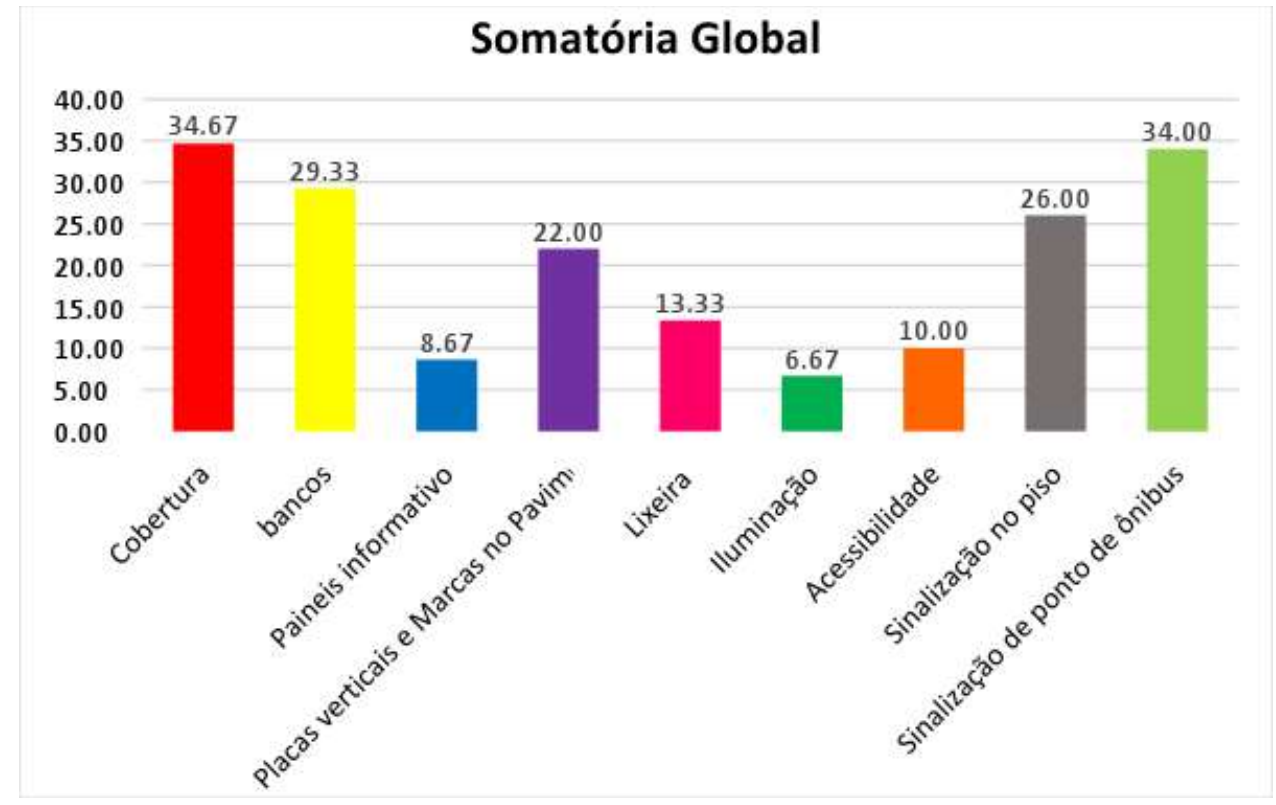

Fonte: Autores; 2017.

Após analisar cada região separadamente, nota-se que algumas tiveram um pouco mais de destaque, como as zonas Sul, Oeste e a região Central. Na zona Sul, os itens como Bancos $(46 \%)$ e Coberturas (43\%) contribuíram para aumentar a média global, enquanto no Centro, uma região de muito movimento e alta circulação de ônibus, $43 \%$ dos pontos de ônibus estavam devidamente sinalizados, $32 \%$ com sinalizações de piso e com destaque também para o número de lixeiras (23\%), quase que o dobro do que foi levantado nas outras regiões. Na zona Oeste, único item que se destacou acima das outras regiões foi o de painéis informativos (13\%). Apesar desse número ser muito longe do ideal, outros itens como Cobertura (36\%) e sinalização de ponto de ônibus (26\%) ajudam a classificar esta como uma das regiões de destaque. Os maiores destaques da zona Norte, Cobertura (32\%) e sinalização de ponto de ônibus (25\%) estão abaixo da média global, enquanto a zona Leste, único destaque que ultrapassa as demais é a de placas verticais e horizontais (26\%), no entanto, Sinalizações de ponto de ônibus $(36 \%)$ e sinalização de piso (29\%) estão acima da média.

Revista ENIAC Pesquisa, Guarulhos (SP), V.7, n.1, jan.- jun. 2018. 
Figura 14 - Gráfico geral

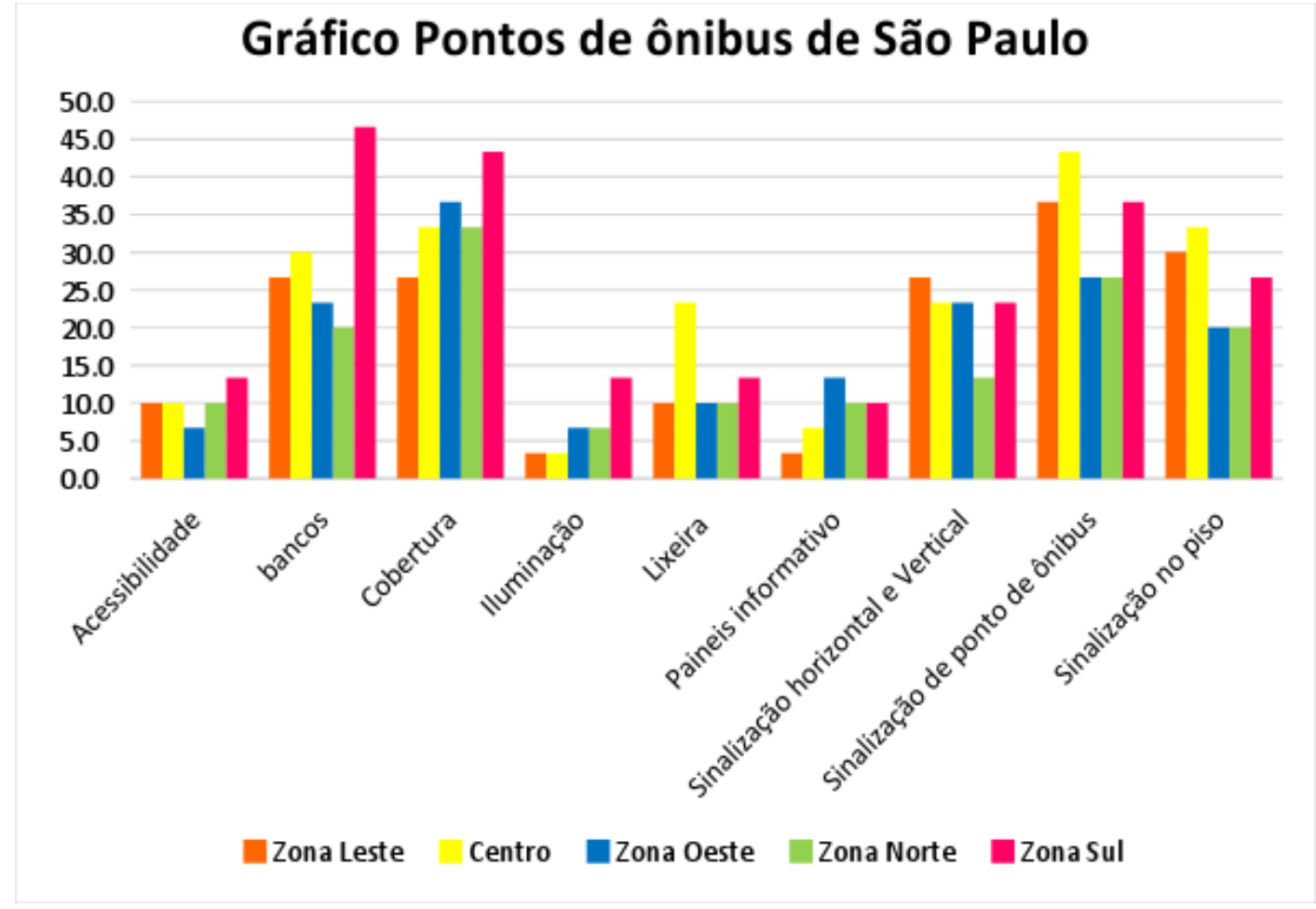

Fonte: Autores; 2017.

Para atingir o ponto ideal que materializamos, ainda há muito trabalho a ser feito, visto que os números estão muito abaixo do que é exigido. Nenhuma região atingiu um patamar satisfatório em conformidade com a norma, muito pelo contrário, a média dos itens pesquisados não ultrapassam 35\%. Itens de grande importância para os usuários, como coberturas, bancos e lixeiras, ou não existem ou estão em situação precárias. Apenas 6,67\% desses pontos tem iluminação, sendo este um item de suma importância para trazer mais segurança aos usuários.

\subsection{RESULTADOS DA PESQUISA DE OPINIÃO}

A pesquisa de opinião deve ser vista sob a ótica amostral, e não tem por finalidade uma inferência estatística aprofundada, visto que a coleta de dados foi feita via internet e pode apresentar algum viés nos dados. Todavia, como o intuito é a percepção do usuário, torna-se possível o uso de tal forma para que tenhamos um panorama sobre nosso objeto de pesquisa.

Revista ENIAC Pesquisa, Guarulhos (SP), V.7, n.1, jan.- jun. 2018. 
A amostra coletada trouxe $43,3 \%$ dos entrevistados na faixa etária dos 21 a 30 anos e $29,8 \%$ dos 31 a 40 anos. Salienta-se que dentre esses, 90,2\% dos usuários se locomovem por meio de ônibus e $47,1 \%$ utilizam desse meio de transporte todos os dias.

Ao serem indagados a respeito dos itens de maior importância em um ponto de ônibus, 97,1\% descreveram que Cobertura é primordial, seguidos por Iluminação (86,5\%), Acessibilidade para Cadeirantes (74\%), Painéis Informativos (70,2\%) e Lixeiras (49\%). A figura 15 ilustra tais percentuais.

Figura 15 - Itens importantes em um ponto de ônibus.

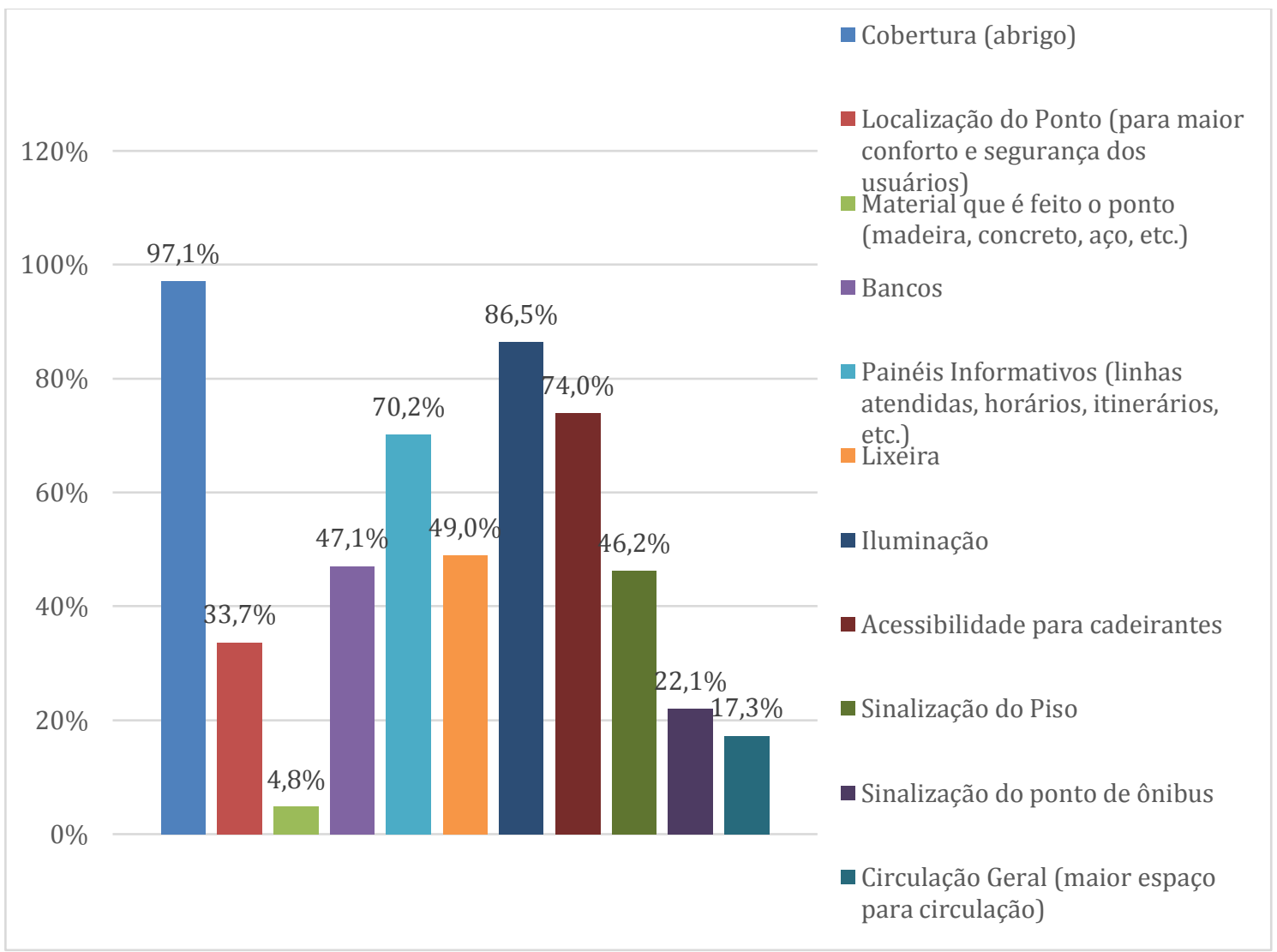

Fonte: Autores; 2017.

Mas quando perguntado a respeito das melhorias necessárias, demonstrada abaixo na Figura 16, 77,8\% responderam que Cobertura e Acessibilidade ainda são questões que ainda precisam ser melhoradas seguindo essa mesma linha, Iluminação $(74,7 \%)$, Painéis Informativos $(66,7 \%)$ e Sinalização de Piso $(52,5 \%)$ são os itens que precisam de maior atenção.

Revista ENIAC Pesquisa, Guarulhos (SP), V.7, n.1, jan.- jun. 2018. 
Com essa pesquisa, foi possível verificar que os usuários de ônibus da cidade de São Paulo têm uma maior necessidade por conforto durante o período em que aguardam pelo coletivo, visto que o item Cobertura foi o mais lembrado durante a pesquisa.

Figura 16 - Gráfico de melhorias que usuários gostariam no ponto de ônibus

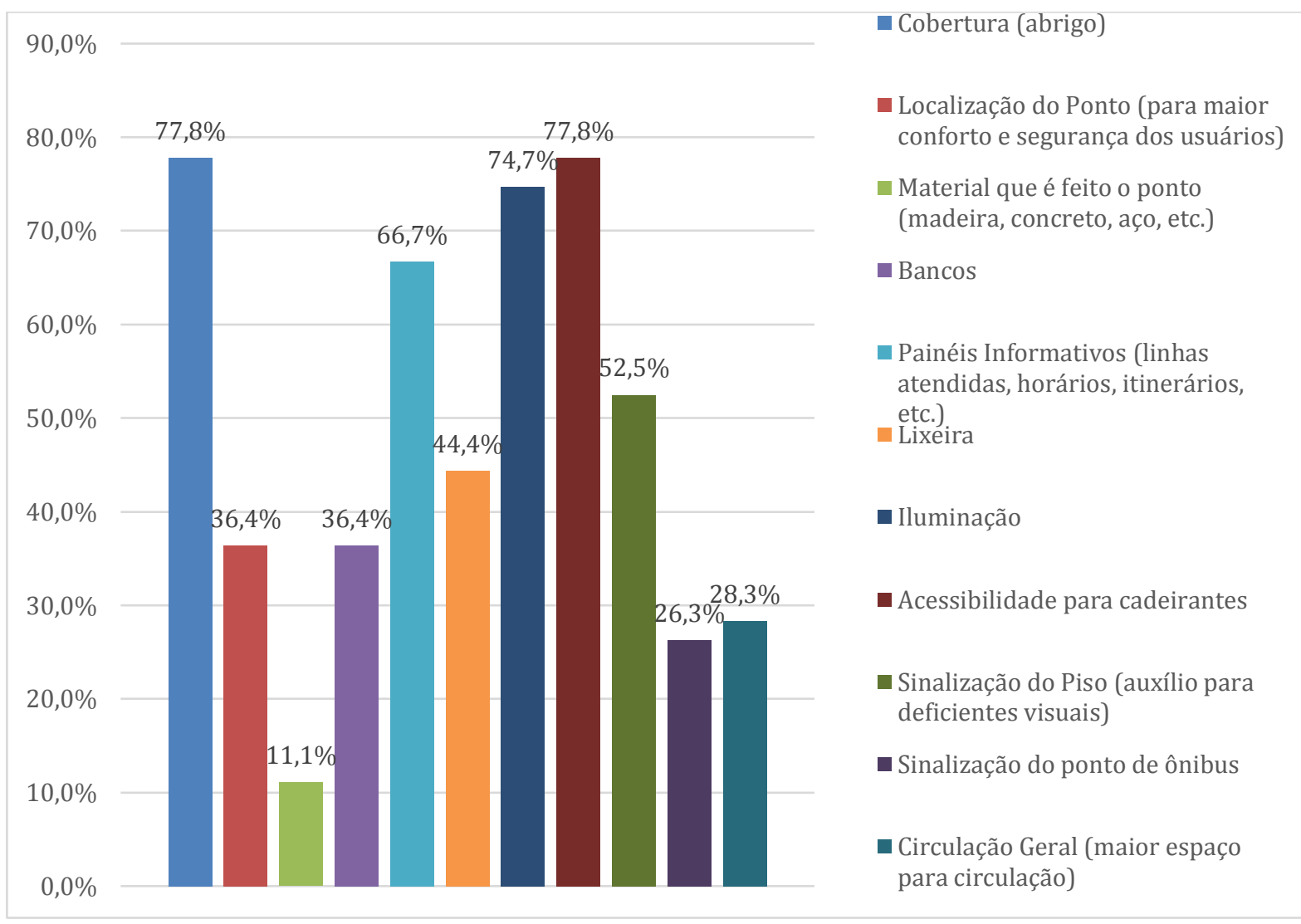

Fonte: Autores; 2017.

\section{CONSIDERAÇÕES FINAIS.}

O objetivo desse trabalho foi realizar uma pesquisa sobre as condições dos pontos de ônibus das cinco regiões da cidade de São Paulo, comparando e analisando as conformidades perante a normatização vigente. Com base nos dados coletados, foram apresentados resultados pouco satisfatórios. Todas as regiões estão abaixo da média em todos os quesitos levantados, o que mostra que ainda há muito a ser melhorado. Os dados apresentados mostram que apesar do problema ser generalizado, há uma distinção em relação a cada região, visto que os bairros mais periféricos da cidade apresentam maiores indicadores mais críticos, como falta de painéis informativos e baixa acessibilidade, e

Revista ENIAC Pesquisa, Guarulhos (SP), V.7, n.1, jan.- jun. 2018. 
estão muito aquém do ideal. Em contrapartida, as regiões mais próximas do centro apresentam alguns pontos de ônibus mais completos, como coberturas, bancos e sinalização.

O estudo aqui apresentado não encerra a discussão sobre o assunto, visto que tinha como foco uma breve abordagem do tema, e cabe sugerir uma pesquisa com uma amostra dentro de uma significância estatística que possa apresentar resultados mais realistas.

\section{REFERÊNCIAS}

ANTUNES, Eloisa Maieski; SIMÕES, Fernanda Antônio. Engenharia urbana aplicada: um estudo sobre a qualidade do transporte público em cidades médias. Urbe. Revista Brasileira de Gestão Urbana, Curitiba, v. 5, n. 2, p.51-62, 2013. Semestral. Disponível em: <http://www2.pucpr.br/reol/pb/index.php/urbe>. Acesso em: 10 out. 2017

ASSOCIAÇÃO BRASILEIRA DE NORMAS TECNICAS. NBR 9050: Acessibilidade a edificações, mobiliário, espaços e equipamentos urbanos. 3 ed. Rio de Janeiro: 2015. $148 \mathrm{p}$.

BOARETO, Renato. Programa Brasil Acessível do Ministério das Cidades. Inclusão: Revista da educação especial, Brasília, [s.n.], v. 3, n. 4, p. 50, junho. 2007.

CONTRAN - CONSELHO NACIONAL DE TRÂNSITO (Brasil). Sinalização horizontal / Contran-Denatran. $1^{a}$ edição - Brasília: Contran, 2007. 128 p.: il. (Manual Brasileiro de Sinalização de Trânsito; 4)

FERRAZ, Antônio Clóvis Pinto; TORRES, Isaac Guillermo Espinosa. Transporte público urbano. São Carlos: Rima, 2004.

IBGE - INSTITUTO BRASILEIRO DE GEOGRAFIA E ESTATÍSTICA. Censo demográfico 2010. Rio de Janeiro, 2010. Disponível em:< https://www.ibge.gov.br/> Acesso em: 01 jul. 2017.

Revista ENIAC Pesquisa, Guarulhos (SP), V.7, n.1, jan.- jun. 2018. 
SÃO PAULO. CET. Secretaria Municipal de Mobilidade e Transporte (Org.). Cetsp: 2017. Disponível em: <www.cetsp.com.br>. Acesso em: 27 abr. 2017.

SÃO PAULO. SPTRANS. Secretaria Municipal de Mobilidade e Transportes (Org.). Número de Linhas. 2016. Disponível em: <http://www.sptrans.com.br/indicadores>. Acesso em: 22 mar. 2017.

TOTAL ACESSIBILIDADE. Disponível em: 〈http://www.totalacessibilidade.com.br〉 Acesso em: 4 jan. 2018.

Revista ENIAC Pesquisa, Guarulhos (SP), V.7, n.1, jan.- jun. 2018. 